\title{
Sobre corpo, reflexidade e poder: um diálogo entre Anthony Giddens e Michel Foucault*
}

\author{
Ivan Marcelo Gomes** \\ Felipe Quintão de Almeida*** \\ Alexandre Fernandez $\mathrm{Vaz}^{* * * *}$
}

\section{Resumo}

Este artigo trata das críticas do sociólogo inglês Anthony Giddens ao filósofo francês Michel Foucault. Vamos discutir se as críticas de Giddens são adequadas tendo em vista as reordenações operadas por Foucault ao longo de sua obra, especialmente em seus escritos mais tardios. Para atingir esse objetivo, assumimos como eixo norteador da reflexão a (in) capacidade da ação individual em relação aos processos (des)subjetivos que tiveram na sociedade moderna seu acontecimento, tomando as noções de sujeito, poder e, por meio deles, a posição que o corpo ocupa nesses discursos. Concluímos com a análise de algumas afinidades eletivas entre a perspectiva teórica de ambos, malgrado as nuanças epistemológicas e políticas existentes entre elas.

Palavras-chave: sujeito, corpo, poder, política.

* O texto é resultado parcial do projeto Teoria Crítica, Racionalidades e Educação II, financiado pelo CNPq (bolsas de produtividade em pesquisa, apoio técnico, iniciação científica, mestrado e doutorado; apoio pesquisa).

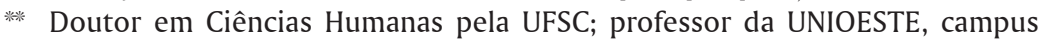
Cascavel; membro do Núcleo de Estudos e Pesquisas Educação e Sociedade Contemporânea (CED/UFSC/CNPq) e do Grupo de Pesquisas em Educação, Cultura, Linguagem e Arte (UNIOESTE).

***** Doutorando em Educação na Universidade Federal de Santa Catarina, bolsista CNPq; membro do Laboratório de Estudos em Educação Física (CEFD/UFES) e do Núcleo de Estudos e Pesquisas Educação e Sociedade Contemporânea (CED/ UFSC/CNPq). Endereço eletrônico: fqalmeida@hotmail.com.

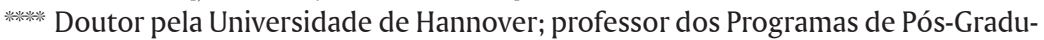
ação em Educação, Interdisciplinar em Ciências Humanas e em Educação Física da Universidade Federal de Santa Catarina; coordenador do Núcleo de Estudos e Pesquisas Educação e Sociedade Contemporânea; pesquisador CNPq. 


\section{Introdução}

$\mathrm{O}$ sujeito, suas condições de possibilidade, bem como sua dignidade e seu lugar social na história, constitui uma temática privilegiada nos debates das Humanidades. Não é para menos, uma vez que a condição de ser sujeito (da história, à história) domina parte do debate intelectual desde que a Modernidade é um tempo que pensa a si mesmo como transitoriedade, como experiência limítrofe entre o eterno e o efêmero, como um tempo que é capaz de falar de si mesmo desde um ponto de vista histórico. Nesse quadro, a interpretação sobre a experiência moderna ganha peso na teoria social contemporânea, seja como afirmação de suas possibilidades como projeto inacabado, ou como crítica que conduz à observação de que estaria esse tempo em seus estertores.

Não é diferente em autores como Antony Giddens e Michel Foucault, que desde distintas tradições se ocuparam do tema, tomando justamente o sujeito como ponto de afirmação e interrogação dessa experiência. Ao ocuparem-se de temáticas que foram comuns, autorizam que se faça algum tipo de cotejamento entre suas assertivas, em especial porque, como será visto logo adiante, o primeiro ocupou-se de criticar o segundo. É aí que se insere o presente trabalho, cujo objetivo é examinar aspectos da crítica de Giddens a Foucault, em especial no que se refere às noções de sujeito e poder e, por meio deles, a posição que o corpo ocupa nesses discursos. Para tanto, apresentamos o percurso que, segundo Giddens, vai da disciplina aos seus impasses, para logo após, ao encontrarmos o tema do sujeito, verificar como este aparece no aparato foucaultiano. Observamos, assim, como a reflexividade, categoria central na obra de Giddens, pode ou não alcançar as lacunas que este supõe haverem sido legadas por Foucault para uma teoria positiva da modernidade e de uma de suas expressões mais próprias, a liberdade. Reservamos as considerações finais para a análise de algumas afinidades eletivas entre a perspectiva teórica de ambos, malgrado as nuanças epistemológicas e políticas existentes entre elas. 


\section{Da disciplina à falta de reflexividade: a crítica giddensiana ao sujeito nos escritos foucaultianos}

É notável a presença de algumas sentenças e passagens de Foucault nos escritos de Giddens, embora o contrário não seja observado. Em boa parte dessas menções, o sociólogo reconhece a relevância das teorizações foucaultianas, embora procure "ampliálas" a partir de outro referencial, de corte mais sociológico, sua profissão afinal. Tais referências, apesar de elogiosas ${ }^{1}$, quase sempre são acompanhadas de alguma advertência cuja intenção, talvez, seja demarcar as diferenças de ambos em relação ao tema do sujeito e à sua (in)capacidade de ação na modernidade.

Na interpretação de Giddens, a modernidade é compreendida dentro de etapas sucessivas (e cada vez maiores) de reflexividade que envolvem os sistemas sociais. Tanto no que se refere a esse dinamismo, em que as ações individuais acontecem, quanto ao próprio conceito de reflexividade, encontra-se presente a categoria do sujeito. Reflexividade necessariamente vincula-se ao agente, ao ator, ao sujeito. A reflexividade institucional é definida por Giddens (2002, p. 26) como " [...] o uso regularizado de conhecimento sobre as circunstâncias da vida social como elemento constitutivo de sua organização e transformação".

É a partir dessa perspectiva (dos laços entre a modernidade e o desenvolvimento de níveis cada vez mais elevados de reflexividade) que são tecidas diversas críticas àquilo que caracterizaria para Giddens o sujeito foucaultiano: sua incapacidade de agir. Giddens é insistente quanto a essa questão. Ele direciona a crítica da impossibilidade de ação do sujeito à obra de Foucault em toda sua extensão e diferentes domínios. A citação a seguir é emblemática:

Penso que é muito importante romper com o estilo 'pós-estruturalista' de pensamento, no qual Foucault permaneceu [...]. Assim

1 "Não devemos perder de vista a importância do trabalho de Foucault, que, na minha opinião, talvez seja a contribuição mais significativa para a teoria do poder da administração desde os textos clássicos de Max Weber sobre a burocracia” (GIDDENS, 1998, p. 318). "As brilhantes inovações de Foucault colocam certas questões-chave de forma jamais pensada, anteriormente" (GIDDENS, 1993, p. 26). 
como as 'transformações epistêmicas' documentadas nos seus primeiros trabalhos, a transmutação do poder emanava de um pano de fundo obscuro e misterioso da 'história sem um sujeito'. Aceito que ‘a história não tenha sujeito' se a frase se referir a uma visão hegeliana da progressiva superação da auto-alienação da humanidade; e aceito o tema da descentralização do sujeito se isso significar que nós não podemos considerar a subjetividade como um dado. Mas não aceito de forma alguma a idéia de uma 'história sem sujeito', se essa expressão significar que as questões sociais e humanas são determinadas por forças das quais os envolvidos estão totalmente inconscientes. É precisamente para combater tal opinião que desenvolvi a teoria da estruturação [...]. O 'método genealógico’ de Foucault, na minha opinião, dá continuidade à confusão que o estruturalismo ajudou a introduzir no pensamento francês, entre história sem um sujeito transcendental e história sem sujeitos humanos conscientes. Entretanto, são coisas muito diferentes. Devemos desconsiderar a primeira, reconhecendo, contudo, a importância fundamental da segunda - a significação que Marx expressou sinteticamente em sua famosa observação de que os seres humanos 'fazem a história, mas não escolhem as condições em que a fazem (GIDDENS, 1998, p. 320).

O problema, continuemos a ler Giddens (1999, p. 307),

[...] é que a história de Foucault parece não ter sujeito ativo nenhum. É história sem ação. Os indivíduos que aparecem nas análises de Foucault mostram-se como que impotentes para determinar seus próprios destinos. Além disso, a apropriação reflexiva da história, fundamental para a história na cultura moderna, não desponta no nível dos próprios agentes.

Pelo exposto nessas duas citações, depreende-se que a suposta ausência de um sujeito reflexivo, que age dentro de determinados limites da estrutura social, acompanha diferentes críticas de Giddens à análise foucaultiana. Não à toa que, para Giddens (2002, p. 146),

A discussão que Foucault faz do manicômio e da prisão relaciona o encarceramento ao impulso de estabelecer a dominação da razão burguesa. [...] por sugestiva e importante que seja, essa posição tem grandes fraquezas. Sem entrar em detalhes, pode-se dizer que não era tanto a 'razão' que estava em questão mas o desenvolvimento da transformação reflexiva. 
Essa apropriação reflexiva da história por parte dos sujeitos nela envolvidos aparece em Giddens como uma estratégia para ampliação da ênfase disciplinar típica das sociedades modernas, tão minuciosamente descritas pela arquegenealogia foucaultiana. Para o sociólogo, ao poder disciplinar do qual Foucault discorre em um livro como Vigiar e punir (1993) não corresponde uma incapacidade de ação reflexiva por parte dos agentes. Em sua leitura, é exatamente a capacidade cognitiva dos agentes que contribui para a construção e difusão dos modelos institucionais em uma determinada estrutura, nos alertando que o que essas instituições têm "[...] em comum com os quadros mais amplos da modernidade é a tentativa de desenvolver o autocontrole reflexivo mesmo entre minorias que podem parecer intrinsecamente recalcitrantes" (GIDDENS, 2002, p.149). "Foucault está errado em atribuir essa semelhança à disciplina como tal” (GIDDENS, 2002, p. 149).

Esta crítica também reaparece em relação aos estudos de Foucault sobre a sexualidade. Em uma menção direta ao primeiro volume da trilogia sobre a História da sexualidade, A vontade de saber (FOUCAULT, 1997a), Giddens afirma que

[...] a tese de Foucault de que a preocupação com a sexualidade torna-se obsessiva e mais ou menos difundida no mundo moderno não parece mais convincente do que aquela que ela pretende em parte substituir [a hipótese repressiva]. Podemos formular uma alternativa às duas hipóteses da seguinte maneira. A 'sexualidade' no sentido moderno foi inventada quando o comportamento sexual 'foi para trás dos bastidores'. Desse ponto em diante, a sexualidade virou propriedade do indivíduo, e mais especificamente do corpo, pois o erotismo em conjunto com a culpa era progressivamente substituído por uma combinação de sexualidade, auto-identidade e propensão à vergonha. [...] O desenvolvimento sexual e a satisfação sexual passam assim a ligar-se ao projeto reflexivo do eu [,constituindol parte do espectro mais amplo do desenvolvimento dos sistemas reflexivos internamente referidos (GIDDENS, 2002, p.152).

Novamente o autor tenta ampliar a abordagem de Foucault recorrendo ao conceito de reflexividade, pois ele trabalha com a tese de que a noção foucaultiana de poder/saber, para a ordenação discursiva de determinados contextos sociais, não deve ser desvincu- 
lada da reflexividade imanente às instituições modernas. Conforme aponta Giddens (1993, p. 39):

Sem negar a sua conexão com o poder, devemos considerá-lo [o discurso] mais como um fenômeno de reflexividade institucional em constante movimento. É institucional por ser o elemento estrutural básico da atividade social nos ambientes modernos. É reflexivo no sentido de que os termos introduzidos para descrever a vida social habitualmente chegam e a transformam - não como um processo mecânico, nem necessariamente de uma maneira controlada, mas porque tornam-se parte das formas de ação adotadas pelos indivíduos ou pelos grupos.

Compreende-se, pois, porque Giddens denuncia o que seria uma excessiva linearidade foucaultiana nas análises que se reúnem sobre a rubrica de biopoder. Para o sociólogo, mesmo que não se possa negar a existência de processos de subjugação em relação aos sujeitos, eles não nos desautorizam a pensar na sua capacidade de reflexão em relação à política geral da verdade no qual está inserido. Por mais importante que seja a análise sobre a disciplina, "Os 'corpos dóceis' que, como Foucault afirmou, a disciplina produzia, mostraram, com frequiência, não serem tão dóceis assim" (GIDDENS, 1998, p. 321): "[...] sua visão de corpo deixa muito a desejar. Ele não consegue analisar a relação entre o corpo e a agência [...]" (GIDDENS, 2002, p. 58); além do que, continua Giddens, não poderíamos estender uma associação tão direta entre a prisão do tipo Panóptico e todas as demais estruturas da sociedade moderna. $\mathrm{O}$ autor enquadra os escritos de Foucault em um modelo analítico que privilegia os aspectos estruturais de análise em detrimento da capacidade de ação dos sujeitos. ${ }^{2}$ Ou seja, na perspectiva giddensiana, o poder só pode ser compreendido a partir das ações de indivíduos e grupos em determinados espaços sociais que apresentam propriedades específicas e formas de reflexividade institucional. Em outras palavras, o poder é expressão daquilo que ele denomina agência, quer

2 Uma curiosidade: Giddens não está sozinho neste tipo de interpretação. Grandes nomes da filosofia atual, como Habermas (2000) e Rorty (1990), consideraram que o trabalho de Foucault guarda semelhanças com uma sociologia do conhecimento que opera de forma funcionalista. 
dizer, não as intenções que as pessoas têm ao fazer as coisas, mas à capacidade de elas realizarem essas coisas, os eventos

[...] dos quais um indivíduo é o perpetrador, no sentido de que ele poderia, em qualquer fase de uma dada sequiência de conduta, ter atuado de modo diferente. $O$ que quer que tenha acontecido não o teria se esse indivíduo não tivesse interferido. A ação é um processo contínuo, um fluxo, em que a monitoração reflexiva que o indivíduo mantém é fundamental para o controle do corpo que os atores ordinariamente sustentam até o fim de suas vidas no diaa-dia (GIDDENS, 1989, p. 7).

Neste enfoque, a ação humana é um elemento fundamental para compreender iniciativas de mudança social, sem desconsiderar os limites colocados para sua realização, assim como a existência de aspectos contingentes e ações não-intencionais que podem influenciar naqueles processos de mudança. Segundo a interpretação de Giddens, seria difícil, senão impossível, compreender estas questões se permanecemos na posição teórica geral desenvolvida por Foucault, pois, conforme defende, o poder em Foucault parece se movimentar de maneiras misteriosas,

[...] e a história, como a realização ativamente elaborada das questões humanas, mal existe. Por isso, aceitamos seus argumentos sobre as origens sociais da sexualidade, mas vamos situá-los em uma estrutura interpretativa diferente. Foucault colocou demasiada ênfase na sexualidade em detrimento do gênero sexual. Silenciou quanto às conexões da sexualidade com o amor romântico, fenômeno intimamente vinculado às mudanças na família. Além disso, sua discussão da natureza da sexualidade permanece em grande parte no nível do discurso - e, nesse nível, as formas mais específicas de discurso. Finalmente, deve-se colocar em questão a sua concepção do eu em relação à modernidade (GIDDENS, 1993, p. 34).

Exposta as críticas de Giddens a Foucault, construídas a partir do eixo do aquele entende ser a (in)capacidade de ação dos sujeitos na modernidade, no tópico seguinte discutiremos seu alcance a partir da interlocução com o próprio filósofo. Experimentaremos, com as ferramentas deste último, a hipótese segundo a qual Giddens trata os escritos daquele autor de modo linear, realizando um 
recorte na obra de Foucault que seria comprobatório de sua crítica e da teoria sociológica que desenvolve, prescindindo, assim, de analisar as reordenações efetuadas pelo criticado, especialmente no domínio tardio de seus escritos.

\section{A crítica giddensiana revisitada à luz do último domínio foucaultiano}

Tornou-se uma espécie de lugar comum entre os comentadores de Foucault, não apenas no Brasil, a compreensão de que sua extensa obra pode ser dividida em três grandes domínios: sua dedicação ao tema dos saberes (ser-saber), tal como se apresenta no livro clássico A arqueologia do saber (1972); depois se voltou ao tema das relações de poder (ser-poder), como em Vigiar e Punir (1993); e, finalmente, ao modo pelo qual cada sujeito relaciona-se consigo próprio (ser-consigo), nos volumes 2 e 3 de História da sexualidade (1997b, 1997c). ${ }^{3}$ A despeito dessa delimitação em seu pensamento, Foucault afirma a inexistência de diferenças substantivas entre os livros que compõem aqueles volumes finais de História da sexualidade e os precedentes. ${ }^{4}$ Quando escrevemos livros, comenta Foucault em entrevista concedida no ano de sua morte,

[...] desejamos que estes modifiquem inteiramente tudo aquilo que pensávamos e que, no final, nos percebamos inteiramente diferentes do que éramos no ponto de partida. Depois nos damos conta de que no fundo pouco nos modificamos. Talvez tenhamos mudado de perspectiva, girado em torno do problema, que é sempre o mesmo, isto é, as relações entre o sujeito, a verdade e a constituição da experiência. Procurei analisar de que modo domínios como os da loucura, da sexualidade, da delinquiência podem entrar em um certo jogo de verdade e como, por outro lado, através dessa inserção da prática humana, do comportamento, no jogo da verdade, o próprio sujeito é afetado. Era este o problema da história da loucura, da sexualidade (FOUCAULT, 2004a, p. 289).

3 Uma exposição detalhada sobre cada um desses domínios (ser-saber, ser-poder e ser-consigo) pode ser obtida em Veiga-Neto (2003).

4 A idéia de uma espiral hermenêutica é bastante útil para expressar como os diferentes domínios foucaultianos se incorporam e se atravessam, alargando as problematizações e as maneiras de trabalhá-las (GROS, 2004a). 
Podemos notar da citação acima que o tema por excelência de sua pesquisa, tomada em seus diferentes domínios, é o sujeito e sua experiência vinculada à política de verdade no qual está inserido. Embora tenha girado em torno do mesmo problema, é preciso reconhecer, contudo, que o filósofo destinou diferentes pesos e medidas àquela relação e aos processos subjetivos que desencadeia. Mesmo que o sujeito constitua o princípio nevrálgico de seu empreendimento teórico, é do próprio Foucault a sentença de que teria insistido demais, quando procurava compreender o poder psiquiátrico, o sistema penal ou a sexualidade infantil, no tema das tecnologias de dominação, pois teria adotado "[...] o ponto de vista tríplice das técnicas, da heterogeneidade das técnicas e de seus efeitos de sujeição, que fazem dos procedimentos de dominação a trama efetiva das relações de poder e dos grandes aparelhos de poder" (FOUCAULT, 1999a, p. 52). Certamente foi essa ênfase foucaultiana nos processos de objetivação e sujeição dos indivíduos que contribuiu para a conclusão, reproduzida pelas críticas de Giddens acima expostas, do caráter de assujeitamento das relações de poder nas mais diversas instituições da modernidade, a ponto de, como diz, não parecer existir sujeito algum na história narrada por Foucault. Daí seu diagnóstico: tratar-se-ia de história sem ação.

No texto A vida dos homens infames (2003), escrito em 1977, antes mesmo, portanto, de Giddens elaborar suas críticas, Foucault mostra-se consciente das dificuldades presentes na analítica até então por ele construída. Essa autocrítica, conforme inúmeros comentadores têm destacado em tempos recentes (SENELART, 1995; ORTEGA, 1999; BODEI, 2000; LAZZARATO, 2000; GROS, 2004a), está relacionada a um conjunto de mudanças em seu pensamento e mesmo em sua vida. É somente no final dos anos de 1970 que ele opera $^{5}$, por exemplo, um deslocamento teórico no eixo do poder: a noção de poder, de cunhagem nietzschiana (como relação de forças),

5 Vale destacar aqui que, no deslocamento operado no interior da analítica do poder, se reveste de grande importância, como anunciam os comentadores, os cursos ministrados por Foucault no Collège de France nos anos de 1978 e 1979, respectivamente, Segurança, território e população (2008a) e Nascimento da biopolítica (2008b), cujos focos situam-se no âmbito das discussões sobre biopolítica (e sua racionalidade) e têm como eixo central o tema da governamentalidade. 
será substituída pela idéia de poder como governo, orientada, e isso é importante na discussão aqui empreendida, para uma teoria $d a$ ação que consiga fugir da fundamentação circular do poder e da resistência em direção a práticas subjetivadoras que visem à liberdade. $\mathrm{O}$ estudo dessas técnicas governamentais apontam efeitos de saber/poder que não são apenas de centralização e dominação, mas também de individualização e subjetivação (RABINOW \& ROSE, 2006); nesse caso, o sujeito já não se constitui de forma heterônoma, como objeto de um aparelho de poder/saber, mas obtém certa autonomia, de modo que possa ser pensando para além desse dispositivo. Um complexo conjunto de práticas de subjetivação, distintas substancialmente da objetivação característica das tecnologias disciplinares, torna-se então a preocupação central de Foucault: “[...] como constituímos diretamente nossa identidade por meio de certas técnicas éticas de si, que se desenvolveram desde a Antiguidade até nossos dias?" (FOUCAULT, 2004a, p. 302). Em suma, Foucault realiza um deslocamento no seu trabalho em direção a uma genealogia do sujeito compreendido como um agente de ações éticas que determinariam a maneira pela qual ele, o indivíduo, deve constituir a si mesmo como o sujeito moral de suas próprias ações. No caso da sexualidade, que Giddens menciona em sua crítica, interessava a Foucault, no final de sua vida, investigar os processos pelos quais os homens aprenderam a se reconhecer como sujeitos da sexualidade, o que pressupunha uma subjetividade que se poderia chamar de prática: "uma maneira de se relacionar consigo mesmo para se construir, para elaborar [uma] história das técnicas de subjetivação, história do olhar a partir do qual eu me constituo para mim mesmo como sujeito" (GROS, 2006, p. 128), algo semelhante àquilo que Giddens reivindicava estar ausente em Foucault ao recorrer à categoria da reflexividade.

Com esse deslocamento, é difícil concordar que, em Foucault, as relações de poder constituem um sistema de dominação que controla tudo e que não deixa espaço para a ação individual, pois no centro daquelas relações, incitando-a, está presente a liberdade. Só assim o outro envolvido na dinâmica do poder poderia ser concebido e mantido até o fim como sujeito da ação, como sujeito ativo que é capaz de influenciar a conduta do outro. Foucault, muito mais 
do que antes podíamos depreender dos seus escritos, tinha clareza agora, no final da vida, da impossibilidade de sermos captados por completo pelo poder e seus efeitos de dominação: é sempre possível modificar sua influência, sob determinadas condições e segundo uma estratégia precisa (FOUCAULT, 1995, 2005). Como resultado dessa reviravolta, modificou-se em sua obra o lugar dos sujeitos no quadro da luta política, uma vez que se tornou imperiosa a necessidade de colocar o problema da vontade individual no cerne mesmo das relações de poder (FOUCAULT, 1999b). Evidencia-se, assim, a possibilidade de um sujeito com capacidade de recusa e resistência, capaz de elaborar sua própria subjetividade, afastada da "verdade" do "sujeito-identidade" e do poder normalizador da lei e das ciências do homem. Compreendido dessa maneira, temos que admitir a inexistência de relações de poder sem recusa ou desacordo em potencial, como a crítica de Giddens em relação a Foucault nos faz supor. Já não há mais efeitos de poder que sejam completamente triunfantes, tornando a dominação incontornável, uma vez que o próprio poder, e as relações que desencadeia, transformaram-se em expressão também de liberdade.

Pelo exposto, não há muita dificuldade em perceber que falta à Giddens uma maior atenção aos desdobramentos existentes na obra foucaultiana, evidente mesmo no momento em que o sociólogo elaborou suas críticas ao filósofo. Talvez ele ficasse mesmo surpreso com a afirmação de Foucault, aqui enunciada, de que é o modo pelo qual o ser humano torna-se um sujeito o tema geral de sua pesquisa (FOUCAULT, 1995). Embora Giddens (1998) esteja correto em ressaltar que entre poder e liberdade não há uma relação do tipo antagônica, uma proposição que Foucault estaria plenamente de acordo, sua crítica à inexistência de um sujeito ativo em Foucault, ou de que tal sujeito seria marcado por um déficit de reflexividade, é inadequada se considerarmos o último domínio de sua obra. O que estamos chamando atenção é que a interpretação de Giddens não considerou a distinção foucaultiana entre jogos estratégicos de poder, estados de dominação e técnicas de governo, uma vez que sua análise crítica centra-se na datada ênfase de Foucault às técnicas e táticas de dominação que, como ele próprio declara, fizeram da positividade das relações de poder, única e exclusivamente, da ordem de um 
poder sobre a vida, sem enfatizar, assim, o espaço para a luta contra determinados efeitos do poder e para o desabrochar das práticas de liberdade presentes em toda e qualquer relação de poder. A critica giddensiana deixa de ser anacrônica somente se endereçada àquele domínio inicial da genealogia foucaultiana, momento em que ele, ao usar palavras inadequadas ou por não ter uma visão mais clara de todo o processo (FOUCAULT, 2004a), fez das relações de poder sinônimo dos estados de dominação, quer dizer, aqueles efeitos ou instrumentos decorrentes da imobilização dos móveis e ambíguos jogos de poder postos em ação na conduta ou governo de si próprio e dos outros, aquele modo de ação sobre ação que pode conduzir à experiências de liberdade. 6

Inadvertidamente à perspectiva giddensiana, talvez, esse deslocamento conceitual em Foucault pôs em cena algumas afinidades eletivas entre o empreendimento teórico de ambos. A discussão de algumas dessas possibilidades é o objetivo das considerações a seguir.

6 É preciso alertar, como fizeram Revel (2006) e Portocarrero (2006), que o tema da resistência e das lutas contra os efeitos de dominação decorrentes das relações de poder não estiveram ausentes em sua totalidade na genealogia do poder realizada em meados dos anos 1970 por Foucault, como nos faz supor alguns comentadores ao considerarem o último domínio de sua obra como a solução para os problemas levantados naquela genealogia. Além de invocar algumas passagens de Vigiar e punir (1993) para corroborar esta advertência, Revel (2006) defende a idéia de que há nesta obra um duplo valor na noção de biopolítica. Por um lado, esta é entendida como um conjunto de biopoderes encarregados de um poder sobre a vida; por outro lado, já neste momento pode-se entender biopolítica, ao menos de forma embrionária, como potência da vida face aos poderes modernos, isto é, como uma política da resistência, da diferença. A ênfase presente no Foucault tardio é que não se trata de colocar o problema da resistência em termos de luta contra efeitos de poder que levam à dominação, mas sim nos termos de produção de novas subjetividades, práticas, linguagens e afetos que nos remetem aos usos e cuidados de si. Essa distinção operada por Revel entre biopoder e biopolítica, tal como também se apresenta em Lazzarato (2000) e Pelbart (2004), vai ao encontro de um debate contemporâneo sobre o conceito de biopolítica que o ressignifica em torno da idéia de um poder da vida, valorizando a capacidade criativa/inventiva do ser humano em se contrapor aos processos de individualização e totalização decorrentes do poder sobre a vida. Uma introdução a esta questão pode ser obtida em Assmann et. al (2007). 


\section{Entre a política-vida e a estética da existência: alguns apontamentos de análise}

No final de sua vida, portanto, Foucault voltou sua atenção à maneira pela qual o sujeito se constitui de forma reflexiva através das práticas de si fornecidas por esquemas sugeridos aos indivíduos para fixar sua identidade, mantê-la ou transformá-la como função de certo número de objetivos e através de relações de autodomínio e autoconhecimento. Embora estes escritos não estabeleçam qualquer tipo de ponte com a atualidade, eles parecem nos indicar a realidade dos processos reflexivos presentes nos contextos póstradicionais em que estamos inseridos, para utilizar da terminologia afeita à sociologia de Giddens (1997). Não temos outra escolha senão decidir como ser e como agir, pois a opção de escapar à individualização e de se recusar a participar de seu jogo está definitivamente fora de cogitação. Se a construção do eu é vista como resultado desse processo reflexivo, uma vez que as subjetividades não são mais "dadas" ou impostas, "somos" o que conseguimos fazer de nós mesmos (GIDDENS, 2002). Isso implicaria, como aventou Foucault em um texto escrito em 1982, na possibilidade de se inventar novas formas de subjetividade ou novos estilos de vida, recusando o tipo de individualidade que nos foi imposto por vários anos (FOUCAULT, 1995). Este é um projeto, em nossa atual sociedade, “[...] conduzido em meio a uma profusão de recursos reflexivos: terapia e manuais de auto-ajuda de todos os tipos, programas de televisão e artigos de revistas" (GIDDENS, 1993, p. 41). E todas essas escolhas referentes ao nosso estilo de vida, desde as mais simples até aquelas maiores e mais importantes, são "[...] decisões não só sobre como agir, mas também sobre quem ser. Quanto mais pós-tradicionais as situações, mais o estilo de vida diz respeito ao próprio centro da auto-identidade, seu fazer e refazer" (GIDDENS, 2002, p.80).

Esta política da escolha, do estilo de vida, instrumentaliza o indivíduo com uma capacidade crítica para o agir que o desobstrui, em princípio, de uma postura de submissão perante os processos mercantis ou discursos oficiais: "[...] no que nos é apresentado como universal, necessário e obrigatório, qual é a parte do singular, contingente e fruto das imposições arbitrárias" (FOUCAULT, 
2005, p. 347). Essa defesa da vontade individual, anteriormente mencionada, caracterizaria, para Foucault (1999b), a atitude crítica da modernidade, quer dizer, a capacidade de não ser excessivamente governado, a arte da desobediência voluntária, de não aceitar “[...] como verdadeiro o que uma autoridade sustenta ser verdadeiro, mas só se forem considerados, em plena autonomia, como boas, as razões para o aceitar" (FOUCAULT, 1999b, p. 3). Se nos reportamos ao projeto reflexivo do eu descrito por Giddens (e que guarda semelhanças com o cuidado de si descrito por Foucault) veremos como tal atitude crítica associada à modernidade está articulada àquilo que ele define como política-vida, ou seja,

[...] a política de uma ordem reflexivamente mobilizada - o sistema da modernidade tardia - que, num individual e coletivo, alterou radicalmente os parâmetros existenciais da atividade social. É uma política de auto-realização num ambiente reflexivamente organizado, onde a reflexividade liga o eu e o corpo a sistemas de alcance global [,] a questões políticas que fluem a partir dos processos de auto-realização em contextos pós-tradicionais, onde influências globalizantes penetram profundamente no projeto reflexivo de eu e, inversamente, onde os processos de auto-realização influenciam as estratégias globais (GIDDENS, 2002, p. 197).

Essa reflexividade do eu se estenderia ao corpo, pois é ele hoje “[...] o portador visível da auto-identidade, estando cada vez mais integrado nas decisões individuais do estilo de vida" (GIDDENS, 1993, p.42). Nesse contexto, em que o corpo desponta como o principal vetor de constituição das subjetividades contemporâneas, o sujeito é chamado para decidir sobre questões constantemente elaboradas pelos sistemas especializados ${ }^{7}$ em relação ao corpo. Suas ações e os cuidados corporais que desencadeiam seriam concebidas como posturas de caráter político e não, unicamente, um alvo do biopoder atual. Os focos da política-vida são as decisões e escolhas individuais

7 Sistemas especializados são sistemas de conhecimento, dependentes de certas regras de procedimentos, que são transferíveis de indivíduo para indivíduo (GIDDENS, 2002). A modernidade atual está cheia deles: professores de educação física, médicos, terapeutas corporais, nutricionistas, etc., que aconselham os indivíduos sobre suas dúvidas a respeito de questões básicas da existência, desde os cuidados com a saúde até regras mais gerais do bem viver. 
nos limiares oferecidos pela estrutura, uma posição, conforme Giddens, muito distinta daquela segundo o qual a disciplinarização dos corpos seria determinada pelos processos estruturais mais amplos (posição, vale ressaltar novamente, que não pode ser reputada a Foucault, sobretudo se considerarmos toda extensão de sua obra). A apropriação reflexiva dos processos de desenvolvimentos corporais impede de tomar o corpo como uma entidade fisiológica fixa, mas o torna profundamente implicado na reflexividade da modernidade. O corpo, como o eu, transforma-se no

[...] lugar da interação, apropriação e reapropriação, ligando processos reflexivamente organizados ao conhecimento especializado sistematicamente ordenado. O próprio corpo foi emancipado - condição para sua reestruturação reflexiva, [mostrando-se como] um elemento fundamental dos debates e lutas da política-vida. É importante destacar esse ponto para ver que o corpo não virou simplesmente uma entidade inerte, sujeita à mercantilização ou à 'disciplina' no sentido de Foucault. Se assim fosse, o corpo seria principalmente um lugar da política emancipatória - a questão poderia então ser a de libertar o corpo da opressão a que teria sido submetido. Nas condições da alta modernidade, o corpo é na realidade muito menos 'dócil'? do que jamais foi em relação ao eu, tendo em vista que ambos estão intimamente coordenados dentro do projeto reflexivo da auto-identidade (GIDDENS, 2002, p. 200-201).

Essas formas através das quais o sujeito constitui a si mesmo como senhor de suas práticas, poderiam ser caracterizadas, se nos voltarmos às teorizações foucaultianas, como um exercício de si sobre si a partir do qual os indivíduos realizam certo número de operações em seu corpo, em seus pensamentos, em suas condutas, procurando se transformar e atingir determinado modo de ser, fazendo de sua vida uma obra que seja portadora de certos valores estéticos e que corresponda a certos critérios de estilo, e cuja representação derive da escolha livre e razoável do próprio sujeito. ${ }^{9}$ Essa

8 Reaparece aqui o equívoco giddensiano. Vale destacar que se trata de um livro publicado por Giddens em 1999, na Inglaterra.

9 O que é isso senão a política vida, quer dizer, uma política das decisões da vida? Decisões estas que derivam, como gostaria Foucault, 1) da liberdade de cada um decidir por qual caminho seguir; 2) da criação de formas moralmente 
prática ascética seria para Foucault uma alternativa às estratégias de subjetivação do poder disciplinar moderno, na medida em que caberia ao indivíduo efetuar determinadas operações sobre si para se transformar e constituir uma forma desejada de existência. É o que se poderia chamar de uma arte da existência ou de uma estética da existência (FOUCAULT, 1997a, 1997b, 1997c, 2004a, 2004b) ou, novamente nos termos de Giddens (2002), de narrativas identitárias, quer dizer, um conjunto relativamente integrado de práticas que um indivíduo abraça não apenas porque elas preenchem necessidades utilitárias, mas sobretudo porque dão forma material a uma narrativa particular da auto-identidade. Na base desse processo, tanto no caso de Giddens, como no de Foucault, está a compreensão do eu como um projeto reflexivo.

Essa temática do estilo de existência ou do estilo de vida revestese de atualidade não somente como categoria histórico-sociológica, como aparece em Giddens, mas também, como em Foucault, toma a forma de uma ontologia, de uma ontologia crítica de nós mesmos, de nosso presente, um ethos que determina nossa forma de ser no mundo. Seria o caso, para Foucault, não mais de uma leitura política em termos de dispositivo de poder político, mas uma leitura ética em termos de prática, de problematização e hermenêutica de si que permite aos indivíduos interrogar-se sobre sua própria conduta, velar por ela, formá-la e subvertê-la, inventando, assim, novos modos de subjetivação, novos estilos de vida individuais para além das objetivações impostas pelas tecnologias de dominação resultantes de certos efeitos do poder. Isto significa que devemos considerar "[...] que as relações de poder/governamentalidade/governo de si e dos outros/relação de si para consigo compõem uma cadeia, uma trama e que é em torno destas noções que se pode, a meu ver, articular a questão da política e a questão da ética" (FOUCAULT, 2004b, p. 307). Embora a possibilidade de construir seus próprios modos subjetivos bem como a chance de modificá-los quando não lhe agradarem mais seja uma questão privada, ela implica em

justificáveis de vida que promovam a auto-realização e; 3) de uma ética relativa à pergunta "como devemos viver" em uma ordem pós-tradicional e contra o pano de fundo das questões existenciais (GIDDENS, 2002). 
vínculos e obrigações sociais. É por isto que a este cuidado de si é preciso recorrer à presença de um outro. Nas análises de Foucault, esse outro é representado pela figura dos chamados mestres da existência, que, mediante conversações, trocas de cartas, aprendizagem em escolas ou enfatizando a formação individual, auxilia aquele que aspira ao cuidado de si próprio ou a criação do seu estilo de viver. Trata-se, portanto, de não renunciar ao mundo e aos outros, mas, por meio da intensificação do contato com o outro, modular diferente a relação com este outro e os demais pelo cuidado de si. Isso é o que Foucault procura nos demonstrar ao descrever como a atividade consagrada a de si pressupunha necessariamente um modo de ação sobre a ação de um outro, se constituindo como uma prática (política) de intensificação das relações sociais.

Entendido como um prolongamento do conceito de governamentalidade (REVEL, 2005), o princípio moral do cuidar-se de si é tomado como base da ação política, do governo da cidade. Em outras palavras, há aqui como que uma submissão da ética à política, pois seria preciso aprender a cuidar de si mesmo para que fosse possível dedicar-se ao cuidado dos outros. Assim, esse cuidado individual e social inscrevia-se em um contexto de liberdade, e não de controle e homogeneização, como o que conhecemos hoje. ${ }^{10}$

Sem dúvida, a ênfase de Foucault nessa temática do cuidado de si e do outro, bem como as considerações de Giddens sobre a política-vida, ambos conceitos que "tomam" os indivíduos como "seres reflexivos" atentos a cada movimento realizado, raramente satisfeitos com seus resultados e sempre prontos a corrigi-los, nos dão a esperança para continuar apostando na capacidade de os indivíduos criarem estratégias de resistência à racionalidade política

10 Como argumenta Ortega (2003), o que caracteriza as asceses contemporâneas, por ele designadas de bioasceses, não é tanto, como nos cuidados de si descritos por Foucault, um desafio aos modos de existência prescritos, um desejo de singularização, de alteridade ou de criação de formas alternativas de subjetividade ou sociabilidade, mas sim uma vontade uniformização e de adaptação à norma, constituição de modos de existência conformistas e egoístas, visando a procura da saúde e do corpo perfeito. O fato de o corpo ter se tornado o principal vetor de constituição das identidades (as bioidentidades) induzem a um conformismo: "[...] o interesse pelo corpo gera o desinteresse pelo mundo. A hipertrofia muscular se traduz em atrofia social" (ORTEGA, 2003, p. 73). 
em voga (o neoliberalismo) e, assim, apostar na invenção de novas formas de vida não completamente capturadas por essa forma de governo que fomenta o individualismo e o consequiente desapego aos outros que conosco habitam o mundo.

\section{Referências}

ASSMANN, S. et al. Corpo e biopolítica: poder sobre a vida e poder da vida. In: Congresso Brasileiro de Ciências do Esporte, XV, 2007, Recife. Anais... Recife: Colégio Brasileiro de Ciências do Esporte, 1 CD ROM, GTT 3.

BODEI, R. A filosofia do século XX. São Paulo: Edusc, 2000.

FOUCAULT, M. A Arqueologia do saber. Petrópolis, Vozes, 1972.

. O sujeito e o poder. In: DREYFUS, H. \& RABINOW, P. (Org.). Michel Foucault. Uma trajetória filosófica: para além do estruturalismo e da hermenêutica. Rio de Janeiro: Forense universitária, 1995. Graal, 1997a.

. História da sexualidade I: a vontade de saber. Rio de Janeiro:

. História da sexualidade II: o uso dos prazeres. Rio de Janeiro: Graal, 1997b.

. História da sexualidade III: o cuidado de si. Rio de Janeiro: Graal,1997c.

. Em defesa da sociedade. São Paulo: Martins Fontes, 1999a.

. Iluminismo e crítica. Roma: Donzelli Editore, 1999b. Tradução provisória do italiano de Selvino José Assmann.

. Ditos e escritos. Estratégia, poder-saber (Vol. IV). Rio de Janeiro: Forense universitária, 2003.

. Ditos e escritos. Ética, sexualidade, política (vol. V). Rio de Janeiro: Forense universitária, 2004a. 
2004b.

. A hermenêutica do sujeito. São Paulo: Martins Fontes,

- Ditos e escritos. Arqueologia das ciências humanas e história dos sistemas de pensamento (vol. II). Rio de Janeiro: Forense universitária, 2005.

Fontes, 2008a.

. Segurança, território e população. São Paulo: Martins

. Nascimento da biopolítica. São Paulo: Martins Fontes, 2008b.

GIDDENS, A. A constituição da sociedade. São Paulo: Martins Fontes, 1989.

. A transformação da intimidade: sexualidade, amor e erotismo nas sociedades modernas. São Paulo: Ed. Unesp, 1993.

. A vida em uma sociedade pós-tradicional. In: BECK, U. et. al. (Org.). Modernização reflexiva: política, tradição e estética na ordem social moderna. São Paulo: Unesp, 1997.

. Foucault, Nietzsche e Marx. In: GIDDENS, A. Política, sociologia e teoria social. São Paulo: Ed. Unesp, 1998.

. Estruturalismo, pós-estruturalismo e a produção da cultura. In: GIDDENS, A. \& TURNER, J. (Org.). Teoria social hoje. São Paulo: Unesp, 1999. Ed., 2002.

. Modernidade e identidade. Rio de Janeiro: Jorge Zahar GROS, F. Situação do curso. In: FOUCAULT, M. A hermenêutica do sujeito. São Paulo: Martins Fontes, 2004a.

. O cuidado de si em Michel Foucault. In: RAGO, M. \& VEIGANETO, A. (Org.). Figuras de Foucault. Belo Horizonte: Autêntica, 2006.

HABERMAS, J. O discurso filosófico da modernidade. São Paulo: Martins Fontes, 2000.

LAZZARATO, M. Del biopoder a la biopolitica. In: Multitudes 1, mars 2000. Disponível em: http://multitudes.samizdat.net/article. php3?id_article $=298$, p. 1-6. Acesso em: 16 mar. 2006. 
ORTEGA, F. Amizade e estética da existência em Foucault. Rio de Janeiro: Graal, 1999.

. Prática de ascese corporal e constituição de bioidentidades.

Cadernos Saúde Pública, Rio de Janeiro, v. 11, n. 1, p. 59-77, 2003.

PELBART, P. P. Vida capital: ensaios de biopolítica. São Paulo: Iluminuras, 2003.

PORTOCARRERO, V. Reabilitação da concepção de Filosofia com ascese no pensamento tardio de Foucault. In: GONDRA, J. \& KOHAN, W. (Org.). Foucault 80 anos. Belo Horizonte: Autêntica, 2006.

RABINOW, P. \& ROSE, N. O conceito de biopoder hoje. Política e Trabalho - Revista de Ciências Sociais, Paraíba, n. 24, p.27-57, abr. 2006.

REVEL, J. Foucault: conceitos essenciais. São Carlos: Claraluz, 2005.

. Nas origens do biopolítico: de Vigiar e punir ao pensamento da atualidade. In: GONDRA, J. \& KOHAN, W. (Org.). Foucault 80 anos. Belo Horizonte: Autêntica, 2006.

RORTY, R. Habermas, Lyotard e a pós-modernidade. Educação e filosofia, Uberlândia, v. 4, n. 8, p. 75-95, jan.jun. 1990.

SENELART, M. A crítica da razão governamental em Michel Foucault. Tempo social (Revista de Sociologia da USP). São Paulo, v. 7, n. 1-2, p. 1-14, 1995.

VEIGA-NETO, A. Foucault e educação. Belo Horizonte: Autêntica, 2003.

\footnotetext{
Abstract

On the body, reflexivity and power: a dialogue between Anthony Giddens and Michel Foucault

This article deals with the British sociologist Anthony Giddens' critical assessments of the work of the French philosopher Michel Foucault. We ask whether Giddens' criticisms are appropriate, in light of the re-elaborations that Foucault himself carried out over the course of his trajectory and particularly in his latter years. For these purposes, we take the (in) capacity of individual action in relation to the (non)subjective processes
} 
which have taken place in modern society as a guideline for our reflections, adopting notions of subject and power to analyze the body's place within these discourses. We conclude with an analysis of some common elements in both theorists' theoretical perspectives, present despite the epistemological and political nuances that distinguish them.

Keywords: subject, body, power, politics. 
